\title{
PENGARUH PENGGUNAAN SOLAR DAN PERTAMINA DEX TERHADAP KINERJA MESIN TRAKTOR
}

\author{
Iqbal Zainal Aripin ${ }^{1)}$, Sjahril Botutihe ${ }^{2)}$ \\ ${ }^{1)}$ Mahasiswa Politeknik Gorontalo, Kampus Puncak Desa Panggulo Bone Bolango \\ ${ }^{2)}$ Tim Pengajar pada Program Studi Mesin dan Peralatan Pertanian, Politeknik Gorontalo
}

\begin{abstract}
ABSTRAK
Mesin traktor merupakan sistim penggerak utama yang banyak digunakan baik untuk sistim transportasi maupun penggerak stasioner. Dikenal sebagai motor bakar yang mempunyai efisiensi tinggi. Di indonesia bahan bakar mesin traktor yang sering di gunakan adalah solar dan pertamina dex yang memiliki sifat yang berbeda. Kedua bahan bakar ini sekilas nampak sama tapi berbeda, namun memiliki karakteristik yang berbeda. Salah satunya adalah angka cetana, dimana pertamina dex lebih tinggi daripada solar. Tujuan dari penelitian ini untuk membandingkan konsumsi bahan bakar dan efisiensi kerja pada mesin traktor Quick G1000s dengan menggunakan solar dan pertamina dex ketika diberikan pembebanan. Metode penelitian yang dilakukan dalam penyusunan tugas akhir ini adalah melakukan pengujian langsung dan observasi terhadap kinerja mesin traktor untuk mengumpulkan data-data yang dibutuhkan. Hasil penelitian Dari hasil pengujian di atas di dapatkan dalam bukaan throttle body standar (low) dengan derajat pengapian yang sama yaitu 16 derajat, di dapatkan pada bahan bakar solar dengan rata-rata putaran mesin 1225rpm, dengan waktu 10 menit 8 detik, mengkonsumsi bahan bakar $111,67 \mathrm{ml}$. sedangkan pada pertamina dex dengan putaran rata-rata mesin 1391,67rpm, dengan waktu 9 menit 7 detik, mengkonsumsi bahan bakar 81,67ml.
\end{abstract}

Kata kunci : solar, pertamina dex, traktor

\section{THE EFFECT OF SOLAR AND PERTAMINA DEX USE ON PERFORMANCE OF TRACTOR MACHINES}

\begin{abstract}
The tractor engine is a main drive system that is widely used for both transportation systems and stationary drives. Known as a fuel motor that has high efficiency. In Indonesia tractor engine fuel that is often used is diesel and pertamina dex which have different properties. Both of these fuels at a glance looks resemble, but have different characteristics. One of them is a fast number, where pertamina is higher than diesel. The purpose of this study is to compare fuel consumption and work efficiency on the Quick G1000s tractor engine using diesel fuel and pertamina dex when given loading. The research method carried out in preparation of this final project is to conduct direct testing and observation performance of the tractor engine, to collect the required data. The results of the test above are obtained in the standard (low) throttle body openings with the same ignition degree of 16 degrees, obtained on diesel fuel with an average engine speed of $1225 \mathrm{rpm}$, with a time of 10 minutes eight seconds, consuming fuel $111.67 \mathrm{ml}$. While at pertamina dex with an average engine speed of 1391.67rpm, with a time of nine minutes seven seconds, consuming fuel $81.67 \mathrm{ml}$.
\end{abstract}

Key words : diesel, pertamina dex, tractor 


\section{PENDAHULUAN}

Di indonesia bahan bakar diesel yang sering di gunakan adalah solar dan pertamina dex yang memiliki sifat yang berbeda. Kedua bahan bakar ini sekilas nampak sama tapi berbeda, namun memiliki karakteristik yang berbeda. Salah satunya adalah angka cetana, dimana pertamina dex lebih tinggi daripada solar. Pertamina dex diklaim cocok untuk mesin diesel dengan teknologi yang tinggi karena memiliki zat pengotor yang rendah, selain zat pengotornya pertamina dex memiliki nilai cetane yang tinggi yaitu sebesar 53 sedangkan solar 48 (keputusan direktur Jendral minyak dan gas bumi nomor $3675 \mathrm{~K} / 24 / \mathrm{DJM} / 2006$ )

Berdasarkan uraian trsebut diatas maka Tujuan penelitian ini adalah sebagai berikut :

1. Untuk mengetahui kinerja mesin traktor ketika menggunakan bahan bakar solar dan pertamina dex

2. Untuk mengetahui efisiensi mesin traktor G1000s ketika di berikan pembebanan.

\section{TINJAUAN PUSTAKA}

Mesin diesel merupakan sistim penggerak utama yang banyak digunakan baik untuk sistim transportasi maupun penggerak stasioner. Dikenal sebagai motor bakar yang mempunyai efisiensi tinggi. Penggunaan mesin diesel berkembang pula dalam bidang otomotif antara lain untuk angkutan barang, traktor, bulldozer, pembangkit listrik di desa-desa kecil generator listrik darurat,dsb. (Purnomo, 2003)

Solar adalah salah satu jenis bahan bakar yang dihasilkan dari proses pengolahan minyak bumi. Kualitas solar Bahan bakar solar di bidang industri banyak digunakan untuk mesin genset, kapal, otomotif atau diesel kendaraan bermotor. Meningkatnya perindustrian akan menyebabkan kebutuhan bahan bakar solar yang semakin meningkat. (Kristanto, 2015)

Pertamina dex merupakan bahan bakar untuk kendaraan bermesin diesel yang memiliki cetane number 53.Jika di banding dengan solar, pertamina dex memiliki kualitas yang tinggi. (Www.pertamina.com., n.d.)

\section{METODE PENELITIAN}

Metode yang di gunakan dalam penelitian ini adalah :

1. Metode penelitian
Metode penelitian yang dilakukan dalam penyusunan tugas akhir ini adalah melakukan pengujian langsung dan observasi terhadap kinerja mesin traktor untuk mengumpulkan data-data yang dibutuhkan

2. Metode pustaka

Metode pustaka adalah suatu cara untuk mendapatkan data-data dengan mengkaji bukubuku referensi yang memuat pembahasan dari masalah yang terkait secara langsung maupun tidak langsung dalam menyusun tugas akhir.

\section{HASIL DAN PEMBAHASAN Persiapan Pengujian}

Pengujian awal yang dilakukan sebelum melakukan penelitian adalah memberikan kondisi alat dan bahan yang digunakan untuk pengujian.Tujuan melakukan persiapan pengujian adalah untuk mendapatkan data yang akurat dalam hasil pengujian. Adapun langkah persiapan alat meliputi :

1. Mesin traktor G 1000 s

Mesin traktor yang di gunakan dalam penelitian ini, telah dilakukan pemeriksaan kondisi mesin, pelumas, sistim pendinginan, dan sistim bahan bakar dengan tujuan agar mesin diesel tersebut dalam kondisi optimal dan siap di uji.

2. Alat ukur

Alat ukur yang digunakan dalam keadaan normal, sebelum alat ukur digunakan untuk pengujian dilakukan sebuah proses kalibrasi untuk mengetahui hasil data secara akurat.

3. Bahan bakar

Bahan bakar yang digunakan dalam pengujian ini menggunakan bahan bakar solar dan pertamina dex, sebelum pengujian dilakukan pengisian bahan bakar mesin diesel dengan kapasitas maksimal.

\section{Tahap Pengujian}

Pada proses pengujian dan pengambilan data untuk kerja mesin traktor dilakukan langkah langkah sebagai berikut:

1. mempersiapkan peralatan yang digunakan dalam proses pengujian data diantaranya tool kit dan lain lain

2. melakukan pemeriksaan terhadap mesin traktor meliputi sistim bahan bakar, pendinginan dan pelumasan

3. menyiapkan bahan bakar yang akan di gunakan dalam pengujian

4. menyalakan mesin traktor yang digunakan untuk pengujian 
5. melakukan pengujian dan pengambilan data berupa putaran mesin,waktu, dan konsumsi bahan bakar

6. mengulang semua proses di atas dengan menggunakan variasi bahan bakar yaitu solar dan pertamina dex

7. setelah selesai semua proses dan mencata datdatanya kemudian mesin traktor di matikan

8. melakukan pemeriksaan ulang terhadap mesin traktor atau alat uji

9. membersihkan dan merapikan alat dan tempat pengujian setelah selesai melakukan pengujian.

\section{Pengujian}

Setelah melakukan pengujian kinerja mesin traktor dilakukan sebuah langkah pemeriksaan pada mesin traktor dan melakukan kalibrasi pada alat ukur agar dapat memperoleh hasil yang akurat. Pemeriksaan kondisi alat dan bahan bertujuan untuk menjaga keselamatan kerja pada saat melakukan pengujian dan pengambilan data.

\section{Pengambilan Data}

Metode pengujian dilakukan dengan membuka gas atau trottle standar (low) dan pengujian mesin traktor di lahan ukuran $15 \times 20 \mathrm{~m}$ dengan $3 \times$ putarn.Langkah ini dilakukan secara berulang-ulang sesuai dengan kebutuhan data yang di ambil serta menggunakan variasi bahan bakar solar dan pertamina dex.

\section{Perhitungan Dayadan Konsumsi Bahan Bakar}

Data daya diperoleh dari hasil pengujian yang telah dilakukan yaitu mengkalikan tegangan dengan arus pada mesin traktor maka akan di dapatkan daya maksimal mesin. Konsumsi bahan bakar dapat diketahui dengan melakukan pengujian menggunakan tangki mini dengan buret sebagai alat penampung bahan bakar agar dapat dilakukan proses bongkar pasang dengan mudah. Proses ini dilakukan pada siang hari di laboratorium mesin dan peralatan pertanian Politeknik Gorontalo.

\section{Pembahasan Hasil Pengujian}

Pada penelitian ini menggunakan mesin traktor quick G1000 s untuk menguji efisiensi mesin menggunakan bahan bakar solar dan pertamina dex.

A. Pengujian putaran mesin dan konsumsi bahan bakar dengan putaran gas (low)/ standar

Dari hasil pengujian di dapatkan dalam bukaan throttle body standar (low) dengan derajat pengapian yang sama yaitu 16 derajat, di dapatkan pada bahan bakar solar dengan rata-rata putaran mesin 1225rpm, dengan waktu 10 menit 8 detik, mengkonsumsi bahan bakar $111,67 \mathrm{ml}$. sedangkan pada pertamina dex dengan putaran rata-rata mesin 1391,67rpm, dengan waktu 9 menit 7 detik, mengkonsumsi bahan bakar $81,67 \mathrm{ml}$

\section{B. Pengujian efisiensi mesin}

Dari hasil penelitian di atas di dapatkan pada pengujian solar, sebelum mesin di jalankan jumlah bahan bakar $600 \mathrm{ml}$, dengan berat jenis solar 494gr. setelah mesin di jalankan pada lintasan $15 \times 20 \mathrm{~m}$ dengan banyak putaran $3 \times$ di dapatkan sisa bahan bakar sebanyak $450 \mathrm{ml}$, dengan berat jenis $461 \mathrm{gr}$, dan bahan bakar yang terpakai sebanyak $150 \mathrm{ml}$ dengan waktu tempuh 10 menit 53 detik.

Sedangkan pada pertamina dex, sebelum mesin di jalankan jumlah bahan bakar $600 \mathrm{ml}$ dengan berat jenis 516gr. Setelah mesin di jalankan pada lintasan $15 \times 20 \mathrm{~m}$ dengan banyak putaran $3 \times$. di dapatkan sisa bahan bakar $570 \mathrm{ml}$ dengan berat jenis $475 \mathrm{gr}$, bahan bakar yang terpakai 30ml dengan waktu tempuh 9 menit 56 detik

Dari hasil pengujian di atas di dapatkan nilai rata-rata pada bahan bakar solar dan pertamina dex.Pada bahan bakar solar di dapatkan putaran mesin sebanyak 1225rpm dengan konsumsi bahan bakar sebanyak $111,67 \mathrm{ml}$ dengan waktu 10 menit 8 detik. Sedangkan pada pertamina dex, putaran mesin sebanyak 1391rpm dengan konsumsi bahan bakar $81,67 \mathrm{ml}$ dengan waktu 9 menit 7 detik

\section{KESIMPULAN DAN SARAN}

\section{Kesimpulan}

1. Pada putaran mesin dan konsumsi bahan bakar dengan putaran gas (low)/ standar antara solar dan pertamina dex didapatkan, pertamina dex lebih menghasilkan putaran rpn yang tinggi dan lebih hemat di bandingkan solar

2. Efisiensi mesin

a. antara solar dan pertamina dex dari segi volume pertamina dex lebih sedikit penggunaannya dia bandingkan solar

b. antara solar dan pertamina dex terdapat perbedaan berat jenis, pertamina dex lebih berat

c. waktu penggunaan antara solar dan pertamina dex di dapatkan pertamina dex lebih hemat waktu di banding solar 


\section{Saran}

1. Volume bahan bakar untuk menguji konsumsi bahan bakar di tambah.

2. Ada uji konsumsi bahan bakar harus ada variasi untuk bahan bakar solar dan pertamina dex untuk putaran gas (low)/standard dan putaran gas (high)/tinggi.

3. Variasi beban pada mesin traktor di tambah

4. Pengambilan data pada proses efisiensi mesin dilakukan dengan lebih presisi lagi

\section{DAFTAR PUSTAKA}

Kristanto, P. (2015). Motor bakar Torak. Yogyakarta: Penerbit ANDI.

Purnomo, 3. (2003). Motor Bakar. Yogyakarta: Teknik Mesin UGM.

Www.pertamina.com. (n.d.). Spesifikasi Bahan akar Pertamina Dex. Diambil dari www.pertamina.com. 